\title{
Coronary Artery Calcification Score and Computed Tomographic Coronary Angiography: A Review and Update
}

\author{
Basil Abu-El-Haija, Bashar Ababneh and James L. Vacek* \\ Department of Internal Medicine and Section of Cardiovascular Diseases, The University of Kansas Hospital and \\ Medical Center, 3901 Rainbow Boulevard, Kansas City, KS 66160, USA
}

\begin{abstract}
Coronary artery disease (CAD) is the leading cause of death in the United States and the world. Identifying new risk factors and improving the screening methods for CAD are continuously evolving processes. The coronary artery calcification (CAC) score, as measured by computed tomographic coronary angiography (CTCA) is of intense interest to clinicians and investigators because of its potential role for diagnosis, risk stratification, and prediction of future mortality and morbidity. Recent studies demonstrate the substantial significance of CAC in CAD and its usefulness as a predictive variable. CAC is a marker of atherosclerosis and gives an estimate of disease severity and extent. It has the potential to provide an objective or quantitative measure of CAD. CTCA offers a noninvasive methodology for defining coronary artery anatomy and providing further definition of CAD extent and severity. Understanding the significance, current role, recent discoveries, and applications of CAC and CTCA is of paramount importance for improved diagnosis and profiling of suspected ischemic heart disease.
\end{abstract}

Keywords: Coronary artery calcification, Coronary artery disease, CT coronary angiography.

\section{INTRODUCTION}

Coronary artery calcification and CAC scores assessed by computed tomography have been active areas of research and investigation in recent years. Because many of the tests for the assessment of CAD are subjective, the CAC score has the advantage of giving an objective value or measurement of CAD as detected by cardiac CT scanning. In this review we address the background and clinical application of the CAC score.

Atherosclerosis is the leading cause of death in the developed world. Statistics have shown that about one-third (80 million) of the population in the United States have cardiovascular diseases [1]. Coronary atherosclerosis alone is responsible for 1 million deaths annually in the United States with an economic burden estimated to be $\$ 142.5$ billion annually [2]. CAC is a marker of atherosclerosis and the extent of calcification is proportional to the extent and severity of atherosclerosis [3]. It is also known that the most common initial presentations of coronary artery disease are myocardial infarction (MI) or cardiac death, and two-thirds of out-of-hospital cardiac arrests occur in patients not known to have cardiac disease $[4,5]$. This suggests that current screening methods, such as the Framingham risk score (FRS), are not detecting a substantial portion of the population who are at risk of ischemic heart events. It appears that progress in the identification and treatment of CAD risk factors in recent decades has resulted in a decline in mortality in the United States [6]; however, there remains a need to identify those people who are being missed with the current risk screening methods.

*Address correspondence to this author at the University of Kansas Hospital and Medical Center, 3901 Rainbow Boulevard, Kansas City, KS 66160, USA; Tel: 913-588-9600; Fax: 913-588-9684;

E-mail: jlvacek@mac.md
We believe that the current role of the CAC score in the diagnosis of coronary heart disease is underestimated, and this test can be applied more broadly. In an attempt to better understand the role and significance of CAC score in ischemic heart disease and atherosclerosis, we did a literature review on this topic as well as its relationship to CTCA.

\section{ATHEROSCLEROSIS AND CORONARY ARTERY CALCIFICATION}

Atherosclerosis is a disease of large and medium-sized muscular arteries that is characterized by endothelial dysfunction and the buildup of lipids, which lead to vascular inflammation and calcification of the vascular wall. It is important to keep in mind that calcified plaques represent older lesions, and newer plaques are more likely to be lipid rich and poor in calcium [2]. Nonetheless, CAC score has been found to give a clinically useful estimate of the atherosclerotic process and the risk of CAD or ischemic heart events [7, 8] (Fig. 1).

\section{CALCIFICATION SCORING AND LIPID CONTROL}

The relation between CAC score progression and lipid control has been studied extensively. The effect of statin therapy on $\mathrm{CAC}$ score was controversial until large prospective trials were conducted. Initial studies suggested that $\mathrm{CAC}$ score could be lowered over time with aggressive lipid-lowering therapy. However, this was not proved by the large retrospective and prospective clinical trials that followed [2]. Most recent trials have shown that statin therapy does not result in regression of coronary calcification even when an aggressive lipid-lowering effect is achieved. Examples of such large prospective clinical trials are the St. Francis Heart Study [9] and the study done by Raggi et al., [10], both of which showed that aggressive statin therapy significantly reduced the lipid profiles of the patients 


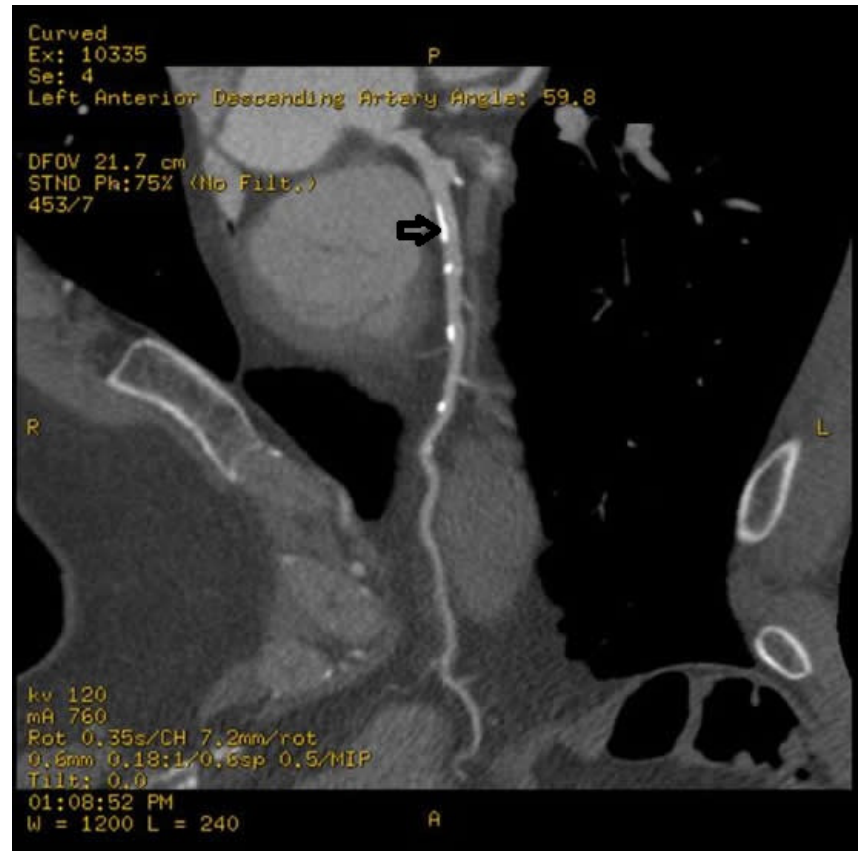

Fig. (1). Coronary artery calcification: Computed tomographic coronary angiography showing calcium deposit in the left anterior descending artery (arrow).

enrolled; however, the patients demonstrated continuous progression of coronary calcification despite the lipidlowering effect.

In a retrospective trial of 66 patients who were followed over 14 months in the late 1990s by Callister et al., [11], it was shown that low-density lipoprotein (LDL) reduction to $<$ $120 \mathrm{mg} / \mathrm{dl}$ achieved by statin therapy did lower the rate of increase of the CAC score; i.e., statin therapy reduced the progression of calcification. On the other hand, Wong et al., showed no role of LDL control in CAC score progression after comparing two groups, one with adequate and the other with inadequate control of LDL cholesterol, but they observed less progression of CAC score with high levels of high-density lipoprotein (HDL) (>1.5 mmol/L [60 mg/dl]) [12].

There is no doubt that aggressive lipid lowering with statins reduces coronary event rates regardless of measurable effect on plaque calcification. The plaque is composed of a lipid core that is partially calcified. It is the lipid core that gets affected with statin therapy and stabilized or reduced rather than the whole plaque body, with the calcium remaining embedded in the plaque. This might explain the disconnection between lipid core regression, calcium alterations, and clinical outcomes with aggressive statin therapy as suggested by the above studies $[2,9,10,11]$.

\section{CAC SCORE FOR RISK STRATIFICATION AND AS A SCREENING TEST}

Many screening methods have been proposed to stratify the risk of cardiac events in asymptomatic patients and accordingly to target therapies to those who would benefit most from them, including aggressive lifestyle changes and the use of antiplatelet therapy and/or cholesterol-lowering agents. The FRS is among the most commonly and widely used tools for risk assessment in clinical practice. The FRS classifies subjects into three groups in terms of 10-year risk of future cardiovascular events: low-risk group $(<10 \%)$, intermediate-risk group $(10 \%-20 \%)$, and high-risk group ( $>$ $20 \%$ ). However, the FRS has its own limitations [13]. Since most of the cardiovascular events occur in individuals at intermediate risk [14], a more accurate assessment for the risk of developing a major cardiovascular event is needed by refining or adding more objective variables. Those in the intermediate-risk group would benefit most from such further risk stratification. CAC score is considered a quantitative predictor of events in patients at intermediate risk of coronary artery disease [15]. Also it was suggested that the predictive value of CAC score for future heart events is superior to the FRS when used in asymptomatic patients [3]. CAC can be identified on plain radiographs, fluoroscopy, and CT scans (Fig. 1), including electron beam tomography or multidetector CT. CT scans can be used as a noninvasive tool to quantify and determine the anatomic distribution of CAC and provide a calcification score, which is a precise number that provides information about cardiac risk by assessment of the total atherosclerotic plaque burden and the amount of plaque volume. Published studies demonstrate a high sensitivity of CAC score for the presence of CAD but a lower specificity for obstructive CAD [16-18].

In the Multi-Ethnic Study of Atherosclerosis (MESA) trial, 6722 men and women between 45 and 84 years of age, who had no clinical cardiovascular disease at entry, were followed for a median of 3.8 years. It was shown that major coronary events were clearly associated with CAC score and no major differences among racial and ethnic groups in the predictive value of calcification scores were detected [7]. In the MESA trial, $90 \%$ of women were classified as low risk by the FRS and had a CAC score prevalence of $32 \%$. Over 4 years CAC score was associated with an adjusted threefold higher risk for coronary heart disease (CHD) events. This indicates that adding CAC score to the FRS would reclassify some women to the high-risk group [7,8].

Taylor et al., reported similar findings in the analysis of the Prospective Army Coronary Calcium (PACC) project [19], a prospective study developed to evaluate the predictive value of CAC score in healthy, unselected, low-risk men. The investigators attempted to define the population who would benefit most from CAC score as a screening tool. Analysis of the PACC project further supported the role and independent predictive value of CAC score as a screening method in lower-risk 40- to 50-year-old men. However, they concluded that CAC score adds predictive power mostly to the people with an FRS $>5 \%$. In this group a significant relation between $\mathrm{CAC}$ score and $\mathrm{CHD}$ was found and they concluded that CAC score was independently predictive of CHD risk in men $<50$ years of age with an FRS exceeding $5 \%$ [19].

With increasing CAC score, the prevalence of significant CAD increases steeply, as shown by other studies [20-22].

The diagnostic value of CAC score for detecting CAD has been studied extensively and also has been compared to other modalities, including exercise electrocardiography, perfusion imaging studies, stress echocardiography, and cardiac magnetic resonance imaging (MRI). Sarwar et al., conducted a meta-analysis to assess the relation between CAC score and adverse cardiovascular outcomes. Eighteen 
studies showed a pooled sensitivity of $98 \%$ for CAC score to detect significant CAD ( $>50 \%$ stenosis) with a negative predictive value of $93 \%$ when results were compared to coronary angiography findings [23].

These outcomes compare well to the diagnostic utility of single-photon emission computed tomography with a sensitivity of $86 \%$ for detecting CAD ( $>50 \%$ stenosis) and a specificity of $46 \%$ to $56 \%$ [24]. Crouse et al., evaluated the diagnostic accuracy of exercise echocardiography as a screening test for CAD ( $>50 \%$ stenosis) and found a sensitivity of $97 \%$ and specificity of $64 \%$ with a positive predictive value of $90 \%$ and negative predictive value of $87 \%$ [25]. Gianrossi et al., conducted a meta-analysis to evaluate the diagnostic accuracy of exercise-induced ST depression. The study included a total of 24,074 patients who underwent both exercise ECG and coronary angiography. $66 \%$ out of this group had an obstructive CAD ( $>50 \%$ stenosis). The results showed a mean sensitivity of $68 \%$ and specificity of $77 \%$ for exercise ECG to detect obstructive CAD [26]. Stress MRI was found to have a sensitivity of $89 \%$ to $93 \%$ and a specificity of $58 \%$ to $80 \%$ for cardiac MRI to detect significant CAD ( $>50 \%$ stenosis) $[27,28]$. From comparison of these studies, CAC score has the highest accuracy among the noninvasive modalities in diagnosing obstructive CAD (Table 1).

Table 1. Sensitivities and Specificities of Different Screening Modalities to Detect Significant Coronary Artery Disease ( $>\mathbf{5 0} \%$ Stenosis)

\begin{tabular}{|c|c|c|}
\hline Modality & Sensitivity & Specificity \\
\hline \hline Coronary artery calcium score & $98 \%$ & $93 \%$ \\
\hline SPECT & $86 \%$ & $46-56 \%$ \\
\hline Exercise echocardiography & $97 \%$ & $64 \%$ \\
\hline Stress MRI & $89 \%-93 \%$ & $58 \%-80 \%$ \\
\hline $\begin{array}{l}\text { Exercise-induced ST depression } \\
\text { MRI: Magnetic resonance imaging; } \\
\text { tomography. }\end{array}$ & $68 \%$ & $77 \%$ \\
\hline
\end{tabular}

It has been suggested that a CAC score of $>400$ is an indication for further diagnostic evaluation (e.g., exercise testing or myocardial perfusion imaging) for CAD [1]. In this population more aggressive risk factor modification could be implemented.

\section{CAC SCORE IN SYMPTOMATIC PATIENTS}

The evidence for the incremental value of CAC score in predicting future cardiac events and its role in diagnosing CAD has not only been observed in asymptomatic individuals but also in symptomatic patients. In a study of 254 patients who presented with new-onset stable typical or atypical angina, CAC score was found to be a significant predictor of $\mathrm{CAD}$ independent of other variables. All patients underwent CTCA and calculation of coronary calcification scores within a week before angiography and 48 $\%$ were found to have obstructive CAD ( $>50 \%$ stenosis) on angiography. The median CAC score was 337 for patients with obstructive CAD. Interestingly, $33.6 \%$ of patients without obstructive CAD had no coronary calcification, whereas only $2.4 \%$ with obstructive CAD had no CAC [22].
The diagnosis of chest pain in women remains a clinical challenge. In a cohort of 883 symptomatic women who presented with chest pain and underwent clinically indicated coronary angiography, 62\% had a normal angiogram [29]. These findings further support the need for alternative screening methods for ischemic heart disease, especially in women. The CAC score has the potential of becoming a useful tool in this setting. In a cohort of 208 patients $(73 \%$ women) who presented with chest pain and already known to have zero CAC score from previous evaluation, underwent conventional coronary angiography. In this group, $80.8 \%$ had either no disease or no significant stenosis $(50 \%$ or more) on coronary angiography. Sensitivity, specificity, negative predictive value (NPV), and positive predictive value (PPV) were 100, 92.3, 100, and 75.5, respectively [30].

Published studies demonstrate that the presence of CAC score is highly sensitive (95-97\%) for the presence of CAD; however, it has a limited specificity (66-75\%) [14, 17]. Therefore, CAC score is a good test in effectively "ruling out" angiographically significant CAD in symptomatic patients and can be used as a filter prior to angiography, with those subjects with negative studies (zero scores) not continuing to invasive angiography.

\section{CAC SCORE AS A PROGNOSTIC TOOL}

The association of CAC score has been studied not only with CAD and coronary heart events, but also with mortality rates. In the above-mentioned studies, especially the MESA trial and the PACC project, the presence of CAC was also found to be related to mortality rates as well as cardiac events. In a cohort of asymptomatic women, CAC score was associated with a higher risk of death. Over a period of 5 years, $80 \%$ of women with CAC scores of $>1000$ were alive compared to $98.4 \%$ of women with no evidence of CAC [8]. Similar results also reported in other studies [15, 31-33].

A recent statement from the AHA $[34,35]$ suggested that all patients with CAC score $>100$ should be considered for statin and aspirin therapy, and possible treatment with angiotensin-converting enzyme inhibitors.

The prognosis of coronary artery disease is closely related to the atherosclerotic plaque burden, and the total number of calcified lesions is strongly associated with mortality [33]. Williams et al., reported that high CAC score in the left main and left anterior descending arteries, but not in the circumflex and right coronary arteries, is associated with an increased risk of mortality [36].

\section{CTCA AND CAC SCORE}

The utilization of CTCA in diagnosing obstructive CAD is a logical progression from employment of the CAC score alone, and accordingly we thought it worth commenting on its current role in patients presenting with chest pain.

Many studies have reported on the sensitivity and specificity of CTCA in detecting obstructive CAD. Most showed that the specificity decreases significantly with increased calcification. In one series, the specificity dropped to $20 \%$ when the CAC score was more than 400 [6]. Heavy calcifications may result in blooming artifacts and obscure the view for the reader, resulting in overestimation of lesion severity and false positive results [37]. However, in patients 
with a CAC score $<10$, CTCA provides excellent diagnostic performance with a very high specificity. The sensitivity is usually in the high 90 s and approaches $99 \%$. In one study, 360 patients between the ages of 50 and 70 years (the majority with obstructive CAD) who presented with stable angina, unstable angina, or non-ST-elevation MI were referred for coronary angiography and all underwent CTCA in addition to standard angiography. For all patients combined, the sensitivity of CTCA to detect significant CAD $(>50 \%)$ was $99 \%$, specificity was $64 \%$, PPV was $86 \%$, and NPV was $97 \%$. It was concluded based on the results of this study that in symptomatic angina patients, a negative CTCA reliably excludes significant CAD [20].

The accuracy of CTCA in the diagnosis of CAD is of paramount importance because the results obtained will further affect the decision of whether more diagnostic tests (such as stress perfusion imaging or angiography) should be undertaken. A recent meta-analysis that compared CTCA with coronary angiography findings for a total of 2045 patients in 23 singlecenter studies showed that CTCA had sensitivities of $90 \%$ or greater and specificities of $88 \%$ or greater, PPV ranged from $69 \%$ to $93 \%$ and NPV from $96 \%$ to $100 \%$ [38].

CTCA can be employed as a screening tool for selected populations in the identification of patients at higher risk for ischemic events. Those people would benefit from further testing and more aggressive risk factor modification [1].

One major limitation of CTCA in the diagnosis of CAD is that most CTCA studies have used a visual estimate of $>50 \%$ diameter stenosis on invasive, selective coronary angiography as the definition of a "significant" stenosis. However, stenoses of $<70 \%$ are typically not flow-limiting, are rarely the cause of ischemia or angina, and usually do not require revascularization. Thus, the sensitivities reported in the literature may not reflect the ability of CTCA to identify those patients with chest pain who will need catheter-based or surgical revascularization.

\section{COMPARISONS OF CTCA WITH OTHER NON- INVASIVE MODALITIES}

CTCA is not specific, but is highly sensitive for the presence of significant CAD. Many studies have compared different noninvasive CAD diagnostic tests, including exercise electrocardiography, stress echocardiography, stress perfusion imaging, stress positron-emission tomography (PET), and stress MRI with CTCA [39- 42]. In those studies each modality finding was compared to angiography finding and the results summarized in Tables $\mathbf{2}$ and $\mathbf{3}$.

Table 2. Positive and Negative Predictive Values of Different Noninvasive Modalities in Detection of Obstructive (50\% Stenosis) Coronary Artery Disease

\begin{tabular}{|c|c|c|}
\hline Modality & $\begin{array}{c}\text { Positive } \\
\text { Predictive Value }\end{array}$ & $\begin{array}{c}\text { Negative } \\
\text { Predictive Value }\end{array}$ \\
\hline \hline CTCA & $94 \%$ & $100 \%$ \\
\hline Treadmill test & $100 \%$ & $67 \%$ \\
\hline Stress echocardiography & $60 \%$ & $54 \%$ \\
\hline Myocardial perfusion exam & $59 \%$ & $55 \%$ \\
\hline
\end{tabular}

CTCA: Computed tomographic coronary angiography.
Table 3. Sensitivities and Specificities of Different Noninvasive Modalities in Detection of Obstructive $(>50 \%$ Stenosis) Coronary Artery Disease

\begin{tabular}{|c|c|c|}
\hline Modality & Sensitivity & Specificity \\
\hline \hline CTCA & $90 \%$ & $88-90 \%$ \\
\hline MRI & $84 \%$ & $85 \%$ \\
\hline Stress MRI & $90 \%$ & $77 \%$ \\
\hline SPECT & $91 \%$ & $69 \%$ \\
\hline
\end{tabular}

CTCA: Computed tomographic coronary angiography; MRI: Magnetic resonance imaging; SPECT: Single photon emission computed tomography.

As discussed in the section on CAC score, the prediction of future cardiac events is a major concern for clinicians; here we have compared the prognostic characteristics of the various screening techniques (Fig. 2). As seen from these data, CTCA compares very favorably with other methodologies used for prognostic screening [43-46].

\section{PROPER UTILIZATION OF CAC SCORE AND CTCA}

The proper utilization of CAC score and CTCA can help guide the clinician in regard to effective diagnosis and risk assessment of potential CAD. As noted earlier, the intermediate-risk group in the FRS is the group that would benefit most from adding a CAC score to their data. Since acute coronary syndrome (ACS) occurs mainly in this group, with a large proportion being missed with the traditional screening methods, CAC score would reclassify some of the intermediate-risk group into high risk, as was observed in the studies mentioned earlier. Despite the fact that doing a CTCA or CAC score is relatively quick and safe, there is the potential risk for radiation-induced cancer. Kim et al., estimated the risk of radiation-induced cancer presuming CAC screening every 5 years from the age of 45 to 75 for men and 55 to 75 for women. They found a mean excess lifetime cancer risk of 42 cases per 100,000 men and 62 cases per 100,000 women [47]. There is a wide variation in the effective radiation dose for CAC score and CTCA, which has been estimated in several studies with a mean of 1 to 6.2 $\mathrm{mSv}$ for CAC score and 4 to $21.4 \mathrm{mSv}$ for CTCA [48].

A reasonable question is when to obtain just a CAC score versus a full CTCA. Since the full CTCA is more expensive and involves more radiation exposure (4 times that of a CAC score alone) it should be avoided if the CAC score alone can suffice. In regard to risk stratification, prognosis, and further diagnostic workup of CAD, obtaining a CAC score alone can be adequate in many instances. However, when evaluating ACS, obtaining a CAC score alone is not sufficient since ACS often occurs in newer, less calcified lesions. In other words, if someone presents with chest pain, CTCA can rule out ACS reliably if it was negative for obstructive disease $(<50 \%$ stenosis). However, a positive CTCA ( $>50 \%$ stenosis) does not necessarily rule in ACS since symptoms usually occur only if the stenosis is flow limiting $(70 \%$ or greater). We believe that the proper utilization of CAC score and CTCA can result in fewer unnecessary angiographies. For example, patients presenting with chest pain but with zero CAC scores and negative CTCA findings can be safely managed without the need for invasive coronary 


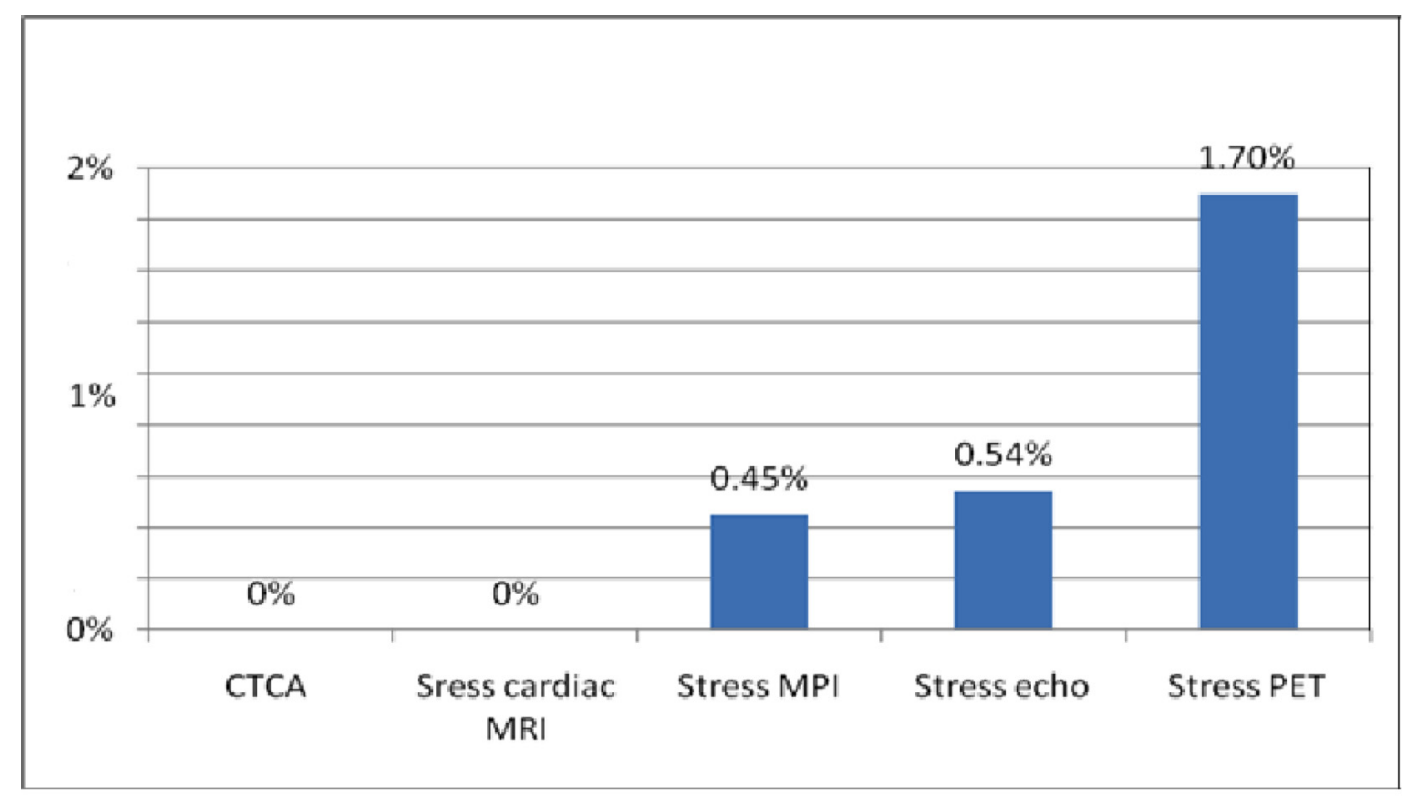

Fig. (2). Annual events rate after negative results with different noninvasive modalities with a follow up duration between 9.2 and 36 months. CTCA: CT coronary angiography; MPI: myocardial perfusion imaging; PET: positron emission tomography.

angiography. The CAC score and CTCA can be used as an effective filter before proceeding to coronary angiography. The high percentage of normal angiographies noted in the studies referenced earlier could possibly be reduced if these patients underwent CAC score and/or CTCA evaluation prior to proceeding toward more invasive diagnostic testing.

A limitation of CTCA is that the diagnostic quality of the images can be reduced by a number of factors, including severe coronary calcification, body habitus, tachycardia, or the presence of coronary artery stents. Specificity is reduced in the presence of coronary artery calcifications (e.g., $86 \%$ versus $53 \%$ for detection of $\geq 50 \%$ stenosis with CAC scores $\leq 400$ versus $>400$ Agatston units) [49]. Other patient-related factors that can interfere with the diagnostic quality of CTCA are irregular heart rhythm (atrial fibrillation or frequent extra systoles) and inability to sustain a breath hold for at least 15 to 20 seconds.

Although CTCA is more expensive than CAC scores, it is still less expensive than other noninvasive modalities. Budoff et al., compared the direct cost of multidetector CT scan to myocardial perfusion imaging in asymptomatic firefighters with positive treadmill. $26.9 \%$ (131) of 495 firefighters had CAC score $>10$ and underwent CTCA. 8\% of 131 of firefighters with CAC score $>10$ had CAD $(>50 \%$ stenosis) and underwent coronary angiography. The myocardial perfusion imaging results were estimated from prior years' experience. The results showed an average cost of $\$ 503$ per person for the CAC score/CTCA pathway and $\$ 1376$ per person for the myocardial perfusion imaging pathway [50].

\section{FUTURE ROLES OF CAC SCORES AND CTCA}

In summary, using a CAC score measurement may be recommended in the intermediate-risk FRS group, as these subjects may benefit from another objective variable that further stratifies the risk of future events. The CAC score might lead to reclassification of those patients to higher risk status and subsequently to more aggressive risk factor modification (i.e., LDL goal $<70$ instead of 100 , better control of blood pressure, more aggressive dietary and exercise intervention) as recommended by scientific statements from the AHA and SHAPE [40, 41]. Furthermore, evaluation for obstructive CAD could be considered in patients with a high CAC score (specifically > 400). Compared to CAC score measurement, using CTCA is probably appropriate to assess obstructive $\mathrm{CAD}$ in symptomatic patients, however it is not recommended in asymptomatic patients. Due to strong evidence of their utility in clinical medicine, it is highly probable that both the CAC score and CTCA will be increasingly utilized in the future and hopefully, additional studies will be conducted to define the appropriate roles for CAC score and CTCA.

\section{ACKNOWLEDGEMENT}

Declared none.

\section{CONFLICTS OF INTEREST}

Declared none.

\section{ABBREVIATIONS}
ACS $=$ Acute coronary syndrome
AHA $=$ American heart association
CAC $=$ Coronary artery calcium
$\mathrm{CAD}=$ Coronary artery disease
CTCA $=$ Computed tomographic coronary angiography
FRS $=$ Framingham risk score
HDL $\quad=$ High-density lipoprotein
LDL $=$ Low-density lipoprotein
MESA $=$ Multi-Ethnic Study of Atherosclerosis
MI $=$ Myocardial infarction 


$$
\begin{array}{ll}
\text { MPI } & =\text { Myocardial perfusion imaging } \\
\text { MRI } & =\text { Magnetic resonance imaging } \\
\text { NPV } & =\text { Negative predictive value } \\
\text { PACC } & =\text { Prospective Army Coronary Calcium } \\
\text { PET } & =\text { Stress positron-emission tomography } \\
\text { PPV } & =\text { Positive predictive value } \\
\text { SHAPE } & =\text { Society for Heart Attack Prevention and } \\
& \text { Eradication }
\end{array}
$$

\section{REFERENCES}

[1] Lloyd JD, Adams R, Carnethon M, et al. Heart disease and stroke statistics-2009 update: a report from the American Heart Association Statistics Committee and Stroke Statistics Subcommittee. Circulation 2009; 119: e21-181.

[2] Gill EJ. Does statin therapy affect the progression of atherosclerosis measured by a coronary calcium score?. Curr Atheroscler Rep 2010; 12: 83-7.

[3] Budoff MJ, Gul KM. Expert review on coronary calcium. Vasc Health Risk Manag 2008; 4: 315-24.

[4] Kannel WB, Schatzkin A. Sudden death: lessons from subsets in population studies. J Am Coll Cardiol 1985; 5: 141B-9.

[5] Rosamond W, Flegal K, Friday G, et al. Heart disease and stroke statistics-2007 update: a report from the American Heart Association Statistics Committee and Stroke Statistics Subcommittee. Circulation 2007; 115: e69-171.

[6] Phillips LM, Mieres JH. Noninvasive assessment of coronary artery disease in women: what's next? Curr Cardiol Rep 2010; 12: 147-54.

[7] LaMonte MJ, FitzGerald SJ, Church TS, et al. Coronary artery calcium score and coronary heart disease events in a large cohort of asymptomatic men and women. Am J Epidemiol 2005; 162: 421-9.

[8] Raggi P, Shaw LJ, Berman DS, Callister TQ. Gender-based differences in the prognostic value of coronary calcification. J Womens Health (Larchmt) 2004; 13: 273-83.

[9] Arad Y, Spadaro LA, Roth M, Newstein D, Guerci AD. Treatment of asymptomatic adults with elevated coronary calcium scores with atorvastatin, vitamin C, and vitamin E: the St. Francis Heart Study randomized clinical trial. J Am Coll Cardiol 2005; 46: 166-72.

[10] Raggi P, Davidson M, Callister TQ, et al. Aggressive versus moderate lipid-lowering therapy in hypercholesterolemic postmenopausal women: Beyond Endorsed Lipid Lowering with EBT Scanning (BELLES). Circulation 2005; 112: 563-71.

[11] Callister TQ, Raggi P, Cooil B, Lippolis NJ, Russo DJ. Effect of HMG-CoA reductase inhibitors on coronary artery disease as assessed by electron-beam computed tomography. N Engl J Med 1998; 339: 1972-8.

[12] Wong ND, Kawakubo M, LaBree L, Azen SP, Xiang M, Detrano R. Relation of coronary calcium progression and control of lipids according to National Cholesterol Education Program guidelines. Am J Cardiol 2004; 94: 431-6.

[13] Kannel WB, D'Agostino RB, Sullivan L, Wilson PW. Concept and usefulness of cardiovascular risk profiles. Am Heart J 2004; 148: 16-26.

[14] Budoff MJ, Diamond GA, Raggi P, et al. Continuous probabilistic prediction of angiographically significant coronary artery disease using electron beam tomography. Circulation 2002; 105: 1791-6.

[15] Raggi P, Gongora MC, Gopal A, Callister TQ, Budoff M, Shaw LJ. Coronary artery calcium to predict all-cause mortality in elderly men and women. J Am Coll Cardiol 2008; 52: 17-23.

[16] Gayed IW, Raslan OA, Bhosale PR, Perrier ND, Wei W, Gladish G. Significant coronary calcification detected using contrastenhanced computed tomography: is it an indication for further investigation? Clin Nucl Med 2010; 35: 404-8.

[17] Cademartiri F, Maffei E, Palumbo A, et al. Coronary calcium score and computed tomography coronary angiography in high-risk asymptomatic subjects: assessment of diagnostic accuracy and prevalence of non-obstructive coronary artery disease. Eur Radiol 2010; 20: 846-54.

[18] Gottlieb I, Sara L, Brinker JA, Lima JA, Rochitte CE. CT coronary calcification: what does a score of " 0 " mean? Curr Cardiol Rep 2011; 13: 49-56
[19] Taylor AJ, Bindeman J, Feuerstein I, Cao F, Brazaitis M, O'Malley PG. Coronary calcium independently predicts incident premature coronary heart disease over measured cardiovascular risk factors: mean three-year outcomes in the Prospective Army Coronary Calcium (PACC) project. J Am Coll Cardiol 2005; 46: 807-14.

[20] Meijs MF, Meijboom WB, Prokop M, et al. Is there a role for CT coronary angiography in patients with symptomatic angina? Effect of coronary calcium score on identification of stenosis. Int $\mathrm{J}$ Cardiovasc Imaging 2009; 25: 847-54.

[21] Fernandez FL, Garcia AA, Bagheriannejad EF, et al. Diagnostic value of coronary artery calcium scoring in low-intermediate risk patients evaluated in the emergency department for acute coronary syndrome. Am J Cardiol 2011; 107: 17-23.

[22] Genders TS, Pugliese F, Mollet NR, et al. Incremental value of the CT coronary calcium scores for the prediction of coronary artery disease. Eur Radiol 2010; 20: 2331-40.

[23] Sarwar A, Shaw LJ, Shapiro MD, et al. Diagnostic and prognostic value of absence of coronary artery calcification. JACC Cardiovasc Imaging 2009; 2: 675-88.

[24] Kang X, Berman DS, Lewin H, et al. Comparative ability of myocardial perfusion single- photon emission computed tomography to detect coronary artery disease in patients with and without diabetes mellitus. Am Heart J 1999; 137: 949-57.

[25] Crouse LJ, Harbrecht JJ, Vacek JL, Rosamond TL, Kramer PH. Exercise echocardiography as a screening test for coronary artery disease and correlation with coronary arteriography. Am J Cardiol 1991; 67: 1213-8.

[26] Gianrossi R, Detrano R, Mulvihill D, et al. Exercise-induced ST depression in the diagnosis of coronary artery disease: a metaanalysis. Circulation 1989; 80: 87-98.

[27] Kim WY, Danias PG, Stuber M, et al. Coronary magnetic resonance angiography for the detection of coronary stenoses. $\mathrm{N}$ Engl J Med 2001; 345: 1863-9.

[28] Hamon M, Fau G, Née G, Ehtisham J, Morello R. Meta-analysis of the diagnostic performance of stress perfusion cardiovascular magnetic resonance for detection of coronary artery disease. J Cardiovasc Magn Reson 2010; 12: 29-38.

[29] Shaw LJ, Merz CN, Pepine CJ, et al. Women's Ischemia Syndrome Evaluation (WISE) Investigators. The economic burden of angina in women with suspected ischemic heart disease: results from the National Institutes of Health-National Heart, Lung, and Blood Institute-sponsored Women's Ischemia Syndrome Evaluation. Circulation 2006; 114: 894- 904.

[30] Cademartiri F, Maffei E, Palumbo A, et al. Diagnostic accuracy of computed tomography coronary angiography in patients with a zero calcium score. Eur Radiol 2010; 20: 81-7.

[31] Shaw LJ, Raggi P, Schisterman E, Berman DS, Callister TQ. Prognostic value of cardiac risk factors and coronary artery calcium screening for all-cause mortality. Radiology 2003; 228: 826-33.

[32] Newman AB, Naydeck BL, Ives DG, et al. Coronary artery calcium, carotid artery wall thickness, and cardiovascular disease outcomes in adults 70 to 99 years old. Am J Cardiol 2008; 101: 186-92.

[33] Budoff MJ, Shaw LJ, Liu ST, et al. Long-term prognosis associated with coronary calcium: observations from a registry of 25,253 patients. J Am Coll Cardiol 2007; 49: 1860-70.

[34] Budoff MJ, Achenbach S, Blumenthal RS, et al. American Heart Association Committee on Cardiovascular Imaging and Intervention; American Heart Association Council on Cardiovascular Radiology and Intervention; American Heart Association Committee on Cardiac Imaging, Council on Clinical Cardiology. Assessment of coronary artery disease by cardiac computed tomography: a scientific statement from the American Heart Association Committee on Cardiovascular Imaging and Intervention, Council on Cardiovascular Radiology and Intervention, and Committee on Cardiac Imaging, Council on Clinical Cardiology. Circulation 2006; 114(16): 1761-91.

[35] Naghavi M, Falk E, Hecht HS, et al. SHAPE Task Force. From vulnerable plaque to vulnerable patient-Part III: Executive summary of the Screening for Heart Attack Prevention and Education (SHAPE) Task Force report. Am J Cardiol 2006; 98: $2 \mathrm{H}-15$.

[36] Williams M, Shaw LJ, Raggi P, et al. Prognostic value of number and site of calcified coronary lesions compared with the total score. JACC Cardiovasc Imaging 2008; 1: 61-9. 
[37] Kuettner A, Burgstahler C, Beck T, et al. Coronary vessel visualization using true 16-row multi-slice computed tomography technology. Int J Cardiovasc Imaging 2005; 21: 331-7.

[38] Stein PD, Yaekoub AY, Matta F, Sostman HD. 64-slice CT for diagnosis of coronary artery disease: a systematic review. Am J Med 2008; 121: 715-25.

[39] Menon M, Lesser JR, Hara H, et al. Multidetector CT coronary angiography for patient triage to invasive coronary angiography: performance and cost in ambulatory patients with equivocal or suspected inaccurate noninvasive stress tests. Catheter Cardiovasc Interv 2009; 73: 497-502.

[40] Kwong RY, Arai AE. Detecting patients with acute coronary syndrome in the chest pain center of the emergency department with cardiac magnetic resonance imaging. Crit Pathw Cardiol 2004; 3: 25-31.

[41] Doesch C, Seeger A, Hoevelborn T, et al. Adenosine stress cardiac magnetic resonance imaging for the assessment of ischemic heart disease. Clin Res Cardiol 2008; 97: 905-12

[42] Adams GL, Trimble MA, Brosnan RB, et al. Evaluation of combined cardiac positron emission tomography and coronary computed tomography angiography for the detection of coronary artery disease. Nucl Med Commun 2008; 29: 593-8.

[43] Lerakis S, McLean DS, Anadiotis AV, et al. Prognostic value of adenosine stress cardiovascular magnetic resonance in patients with low-risk chest pain. J Cardiovasc Magn Reson 2009; 11: 37-48.

[44] Chow BJ, Al Shammeri OM, Beanlands RS, et al. Prognostic value of treadmill exercise and dobutamine stress positron emission tomography. Can J Cardiol 2009; 25: e220-4.
[45] Maffei E, Seitun S, Martini C, et al. Prognostic value of CT coronary angiography: focus on obstructive $v s$ nonobstructive disease and on the presence of left main disease. Radiol Med 2011; 116: $15-31$.

[46] Metz LD, Beattie M, Hom R, Redberg RF, Grady D, Fleischmann KE. The prognostic value of normal exercise myocardial perfusion imaging and exercise echocardiography: a meta analysis. J Am Coll Cardiol 2007; 49: 227-37.

[47] Kim KP, Einstein AJ, Berrington de González A. Coronary artery calcification screening: estimated radiation dose and cancer risk. Arch Intern Med 2009; 169: 1188-94.

[48] Einstein AJ, Moser KW, Thompson RC, Cerqueira MD, Henzlova MJ. Radiation dose to patients from cardiac diagnostic imaging. Circulation 2007; 116: 1290-305.

[49] Budoff MJ, Dowe D, Jollis JG, et al. Diagnostic performance of 64-multidetector row coronary computed tomographic angiography for evaluation of coronary artery stenosis in individuals without known coronary artery disease: results from the prospective multicenter ACCURACY (Assessment by Coronary Computed Tomographic Angiography of Individuals Undergoing Invasive Coronary Angiography) trial. J Am Coll Cardiol 2008; 52: 172432.

[50] Amemiya S, Takao H. Computed tomographic coronary angiography for diagnosing stable coronary artery disease; a costUtility and cost-effectiveness analysis. Circ J 2009; 73: 126370.

(C) Abu-El-Haija et al.; Licensee Bentham Open.

This is an open access article licensed under the terms of the Creative Commons Attribution Non-Commercial License (http://creativecommons.org/licenses/by$\mathrm{nc} / 3.0 /$ ) which permits unrestricted, non-commercial use, distribution and reproduction in any medium, provided the work is properly cited. 